\title{
Análise de sustentabilidade do Sistema Condominial de Esgoto da COHAB Lindóia
}

\section{Sustainability analysis of COHAB Lindóia's Condominial Sewage System}

\author{
Barbosa, Matheus'; Medvedovski, Nirce ${ }^{2}$; \\ 1 Universidade Federal de Pelotas, Benjamin Constant 1359, Brasil, \\ matheusbarbosa.engenharia@gmail.com \\ 2 Universidade Federal de Pelotas, nirce.sul@gmail.com
}

\begin{abstract}
RESUMO
Os conjuntos habitacionais promovidos pela Companhia de Habitação do Estado do Rio Grande do Sul (COHAB-RS), em Pelotas no início da década de 80, e financiados pelo Banco Nacional de Habitação (BNH), apresentam dentre suas diversas especificidades, o Sistema Condominial de Esgoto, que difere do sistema comumente utilizado. Este artigo é parte integrante da pesquisa de mestrado intitulada "O caso de infraestrutura de saneamento do Conjunto Habitacional Lindóia: Uma perspectiva mais sustentável do Sistema Condominial de Esgoto" e pretende contribuir com a elaboração de critérios de análise de sustentabilidade para a etapa seguinte da pesquisa. A metodologia utilizada foi a revisão de literatura, no qual se relacionou o estado da arte de Sachs (1993), que trabalha com o tema de desenvolvimento sustentável, com Melo (1994) e Vasconcelos (1995) que trabalham com o Sistema Condominial de Esgoto. Relacionou-se então, a sustentabilidade social, econômica, ambiental e política, com as ideias de produção e operação do Sistema Condominial de Esgoto. Conclui-se que a concepção deste sistema está diretamente relacionada com o desenvolvimento sustentável, entretanto, na época de implementação do mesmo, o tema da sustentabilidade não era abordado, concluindo-se que o Sistema Condominial de Esgoto foi precursor de uma proposta de desenvolvimento sustentável.
\end{abstract}

Palavras-chave: sustentabilidade, sistema condominial de esgoto, APO.

\begin{abstract}
The housing complex promoted by the Housing Company of the State of Rio Grande do Sul (COHAB-RS), in Pelotas in the early 1980's, and financed by the National Housing Bank (BNH), has among their various specificities the Condominial System of sewage, which differs from the system commonly used. This article is an integral part of the master's research entitled "The case of the Lindóia Housing Complex: A more sustainable perspective of the Sewage Condominial System" and intends to contribute to the elaboration of sustainability analysis criteria for the next step of the research. The methodology used was the literature review, which related the
\end{abstract}

${ }^{1}$ BARBOSA, Matheus; MEDVEDOVSKI, Nirce. Análise de sustentabilidade do Sistema Condominial de Esgoto da COHAB Lindóia sob a ótica da sustentabilidade. In: II SIMPÓSIO NACIONAL DE GESTÃO E ENGENHARIA URBANA: SINGEURB, 2019, São Paulo. Anais... Porto Alegre: ANTAC, 2019. 
state of the art of Sachs (1993), who works with the theme of sustainable development, with Melo (1994) and Vasconcelos (1995) who works with the Condominial Sewage System. Social, economic, environmental and political sustainability were related to the ideas of production and operation of the Condominial Sewage System. It is concluded that the design of this system is directly related to sustainable development, however, at the time of its implementation, the theme of sustainability was not addressed, concluding that the Condominial Sewage System was the precursor of a proposal for sustainable development.

Keywords: sustainability, sewage condominium system, POE.

\section{INTRODUÇÃO}

Ao longo das últimas décadas tem crescido a preocupação com o desenvolvimento de cidades mais sustentáveis e com estudos que contemplam a inserção de estratégias e inovações que contribuam para a sustentabilidade em áreas urbanas. Entretanto, essas estratégias muitas vezes estão ligadas a promoção e produção de novos empreendimentos, e não dialogam com o ambiente já construído e com serviços urbanos de infraestrutura já existentes.

A busca de implementação ou requalificação dos sistemas urbanos de infraestrutura de uma forma mais sustentável deve ter como base o conceito do desenvolvimento sustentável urbano, em que se propõem recomendações e ações que estão relacionadas a uma visão social, econômica, ambiental e política (SACHS, 1993).

Este trabalho é parte integrante da pesquisa de mestrado intitulada "O caso de infraestrutura de saneamento básico do Conjunto Habitacional Lindóia: Uma perspectiva mais sustentável do Sistema Condominial de Esgoto", cujo interesse é analisar a implementação do serviço de esgoto sanitário na COHAB Lindóia, em Pelotas, verificando se esses serviços estão de acordo com princípios de sustentabilidade e compatíveis com as necessidades, vivências e usos dos espaços pelos moradores.

Os conjuntos habitacionais de interesse social da última fase da Companhia de Habitação do Estado do Rio Grande do Sul (COHAB-RS) foram entregues em meados da década de 80 , no período final do Banco Nacional de Habitação (BNH), e destinado à população de baixa renda. Segundo Medvedovski (1998) e Chiarelli (2014), sua última fase delegou as decisões de localização e projeto à iniciativa privada, mediante licitação pública, originando mais de 6000 unidades em Pelotas. Dentre estas, 1.778 unidades foram construídas na COHAB Lindóia.

De acordo com Medvedovski (1998), o projetista responsável pelos conjuntos habitacionais de Pelotas, optou por casas geminadas em fitas com variação de um a três dormitórios. $O$ conjunto é constituído de 128 fitas, que agrupam de 16 a 32 unidades, que se justapõem pelos pátios de fundo, local onde foram instalados os ramais condominiais (Figura 1). 


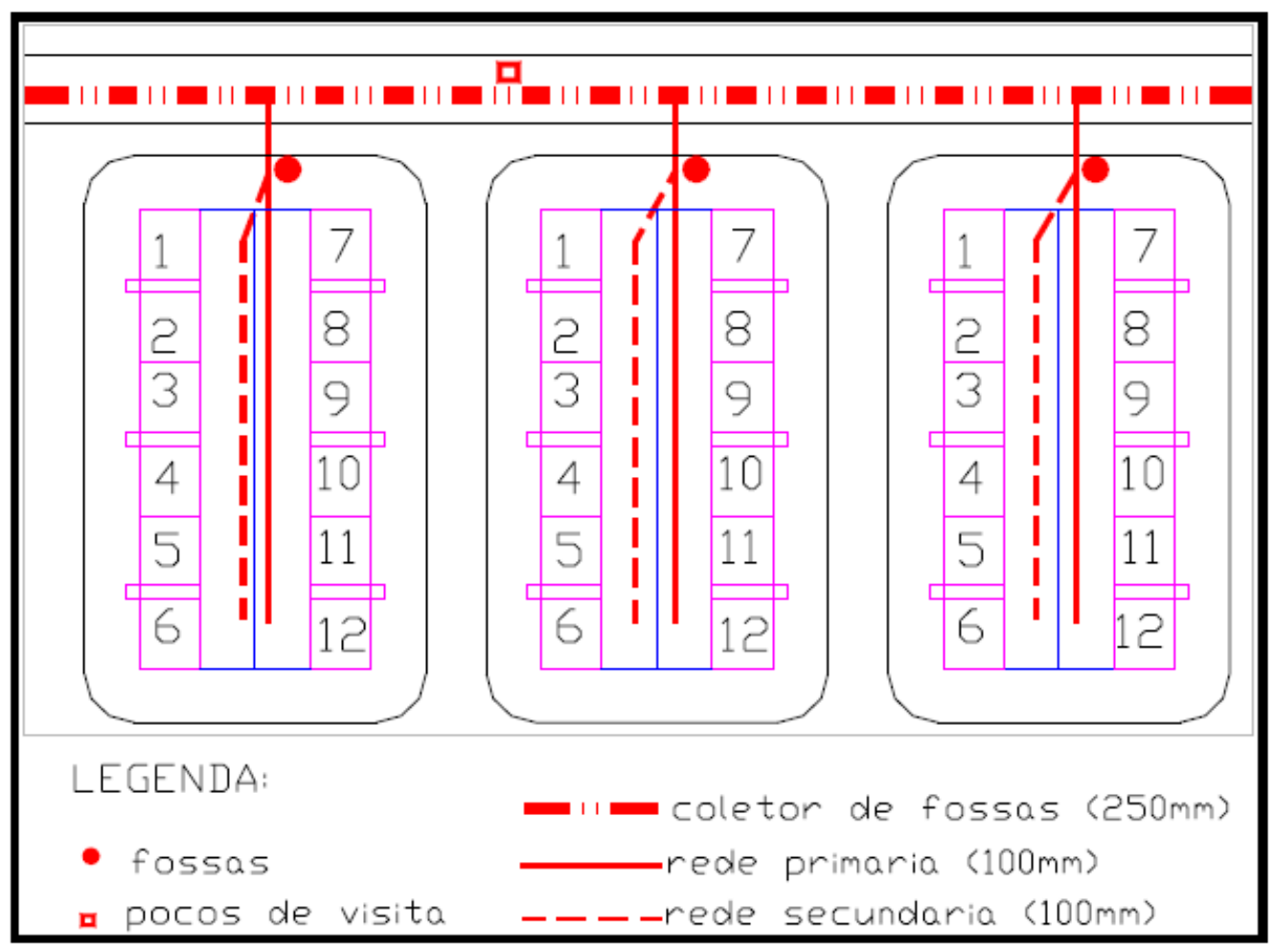

Fonte: Medvedovski (1998)

Na época do projeto da COHAB Lindóia foi proposta a utilização do sistema de Ramais Condominiais, já utilizado no Nordeste pelo engenheiro Mello (1994) e abordado na tese de Vasconcelos (1995). Esse sistema tem como principais concepções a democratização do serviço, redução dos custos, preservação ambiental e descentralização das decisões.

Para Scaramussa e Henkes (2014), o sistema de Ramais Condominiais conferem características mais sustentáveis, adaptabilidade às diferentes situações físicas e condições socioculturais. Em consequência da participação dos usuários, o condomínio torna-se uma unidade social de facilitação de decisões coletivas e ações de organização enquanto comunidade.

Salienta-se que na época de implementação da COHAB Lindóia, o conceito de sustentabilidade e de desenvolvimento sustentável, da forma como é abordado atualmente, não era discutido e começou a ser debatido, de forma inicial em Estocolmo, em 1972. Acselrad (1999) afirma que os conceitos de sustentabilidade ganharam notoriedade após 1992, ou seja, 8 anos após a construção da COHAB Lindóia.

Este trabalho tem por objetivo geral realizar uma revisão bibliográfica dos trabalhos de Melo (1994) e Vasconcelos (1995), os quais abordam o sistema dos ramais condominiais e olhar suas premissas sanitárias sob a ótica das classificações dos tipos de sustentabilidade explorados por Sachs (1993), autor precursor no desenvolvimento sustentável. Nesse sentido, este trabalho pretende contribuir com a elaboração de critérios para análise de sustentabilidade do Sistema Condominial de Esgoto da COHAB Lindóia, que posteriormente serão utilizados em entrevistas com os moradores e gestores públicos.

\section{METODOLOGIA}

O método utilizado neste trabalho é revisão da literatura. De modo geral, este método consiste em uma metodologia fundamentada em livros, artigos e teses. Na presente pesquisa utilizou-se as bibliografias de Sachs (1993), Melo (1994) e Vasconcelos (1995).

Quanto ao tipo de revisão de literatura, o trabalho caracteriza-se como revisão integrativa, 
no qual integra resultados de pesquisas anteriores, combinando assim os dados de diferentes literaturas para preencher a lacuna de conhecimento sobre o tema de sistemas condominiais de esgoto mais sustentáveis.

A metodologia consistiv em cinco etapas distintas:

A primeira foi a identificação do foco, no qual definiu-se o tema a ser trabalhado. Neste caso, os temas escolhidos foram sustentabilidade e o sistema condominial. A segunda etapa consistiu no estabelecimento de critérios para a seleção dos autores, pois para realizar a integração dos temas é necessário que os autores possuam áreas afins e que se complementem. A terceira etapa abrangeu a escolha de informações a serem extraídas dos autores e as informações coletadas foram os conceitos gerais dos tipos de sustentabilidade (social, política, ambiental, econômica), em conjunto com as premissas dos ramais condominiais. Já a quarta etapa compreendeu a análise e interpretação da bibliografia, de forma crítica e concisa para que atinja o objetivo proposto. Por fim, a última etapa é a apresentação da revisão, com o intuito de reunir e sintetizar as evidências coletadas na literatura e divulgar o resultado produzido.

\section{RESULTADOS}

Para facilitar a compreensão do conceito de sustentabilidade, usou-se as definições de Sachs (1993) que divide a sustentabilidade em cinco classificações e está presente na Agenda 21 Brasileira: a ambiental, econômica, ecológica, social e política. Entretanto, após revisar a literatura, optou-se neste trabalho pela união da sustentabilidade ambiental com a sustentabilidade ecológica. Por fim, uniu-se as objetivações da implementação e gestão do Sistema Condominial de Melo (1994) e Vasconcelos (1995), ao longo de cada tipo de sustentabilidade definida por Sachs (1993).

\subsection{Sustentabilidade ambiental}

- Proteção dos recursos naturais

A degradação ambiental ocorre, principalmente, quando as águas drenadas não são coletadas adequadamente. Como consequência, ocorre a inviabilização do corpo hídrico como manancial de abastecimento da população. O uso desta fonte contaminada ocasiona danos à saúde do usuário. Nesse sentido, os canais, riachos e bacias hidrográficas, que estão na área urbana, são polvídos devido a canalizações não conectadas a estações de tratamento.

- Presença do esgoto não coletado nas áreas coletivas e públicas

Os esgotos não coletados acabam se dirigindo às calhas de drenagem, formando cloacas que atraem também o lixo produzido pela população, produzem vegetação que implica em focos de mosquitos e perda da capacidade de transporte do material erodido, causando transbordamento. As águas infectadas passam então a ocupar o espaço público, contaminando a população e originando doenças como: cólera, meningite, disenterias, dentre outras.

\subsection{Sustentabilidade social}

- Padrão do serviço

Os sistemas convencionais acabam por atender uma camada com maior poder aquisitivo e excluem os moradores menos favorecidos. O sistema dos ramais condominiais propõe-se então, a utilizar um modelo orientado pelas características econômicas da população, capaz de determinar um menor investimento e também atender maiores exigências, a partir de investimentos econômicos complementares, diretamente mantidos pelos interessados.

- Ensino e Conscientização da população

O Brasil possui grande déficit educacional, e é evidente que não há ensino e conscientização por parte da população nas questões sanitárias, principalmente em comunidades com menor poder aquisitivo. Visando a minimização deste desconhecimento, é necessário 
conscientizar a população, bem como instruí-la sobre o apoio técnico existente.

- Formulação de pactos e alternativas

Trata-se de uma concepção de alternativas democráticas com participação de todos os envolvidos, formulando assim um "pacto inicial". Este pacto visa contemplar os planos físicos técnicos (alternativas de atendimento), decisões políticas (regras, direitos, deveres e responsabilidades), parcerias institucionais de gestão (estado, instituições privadas), para que assim possa ser instaurado um plano de ação inicial.

\subsection{Sustentabilidade Política}

- Democratização

A democratização tem por consequência a participação comunitária nas decisões e ações sobre o serviço. A participação surge como uma necessidade para reorganizar o modelo, a partir de novos papéis e responsabilidades de instituições e moradores que passam a dividir as demandas, carências e déficits existentes. Com isto, a participação poderá vir a ser um estímulo para integração social no que se refere a organização política do bairro, garantindo assim a eficiência do serviço.

- Descentralização

Entende-se que sistemas descentralizados tornam-se mais eficientes, pois delegam em níveis hierárquicos diferenciados, responsabilidades e capacidade de tomada de decisões a todos os atores. Destaca-se o papel do poder municipal como articulador local, além de regulador e controlador dos sistemas locais, integrando o poder público, usuários e prestadores de serviços.

\subsection{Sustentabilidade Econômica}

- Adequação à realidade

Através da participação comunitária pode-se realizar a adequação das soluções face a realidade, minimizando investimentos, garantindo assim o atendimento pleno e adequado. Para adequar o sistema e suas soluções à realidade presente, é necessário a compreensão dos problemas e necessidades de cada contexto urbano.

- Operação e manutenção

A operação e manutenção parte do pressuposto de que se há uma correta negociação entre as partes envolvidas, na concepção do projeto, nas alternativas empregadas e se bem fiscalizados durante a operação, o sistema tende a não apresentar problemas. Cabe então, no pacto, a formalização da decisão de como será a manutenção, bem como a sua periodicidade.

- Integração de ações

O sistema de esgoto é um potencial integrador de outros serviços urbanos. A integração de serviços possibilitaria: a minimização de desperdícios dos sistemas de água para que haja menor custo de investimentos; realizar a construção dos sistemas de esgotos anteriormente a drenagem e pavimentação para que o sistema de coleta possa minimizar a necessidade de canalizações enterradas para a drenagem; otimizar a utilização de efluentes. Essa integração busca ganhos de investimentos e diminuição de custos, auxiliando a eficiência de diversos serviços e seus agentes promotores.

- Oportunidade de realização e investimentos

É necessário entender de qual agente está partindo a iniciativa para requalificação, suas intenções, recursos disponíveis e a origem destes recursos, bem como o plano de continuidade a longo, médio e curto prazo. Essas informações devem ser exploradas visando a conhecer a iniciativa, os investimentos, o nível de informação sobre o sistema por parte do agente promotor, e verificar os requisitos e limitações de implementação. 


\section{CONCLUSÕES}

Conclui-se que todas as premissas identificadas por Melo (1994) e Vasconcelos (1995) na concepção do modelo condominial de esgoto, vão ao encontro das quatro dimensões gerais de sustentabilidade produzidas por Sachs (1993). Entretanto o Sistema dos Ramais Condominiais, implementado na COHAB Lindóia, em Pelotas, não tinha a preocupação em ser mais sustentável, mas sim a preocupação de produzir um sistema que fosse de menor custo, resultando em unidades habitacionais mais rentáveis para as construtoras e incorporadoras.

Nesse contexto, esse sistema foi só implementado na sua parte física, localizada ao fundo dos lotes, num pátio concebido originalmente como coletivo, ficando sem ser implementado os aspectos ambientais, sociais, econômicos, políticos. Medvedovski (1988) identificou a ocupação dos espaços coletivos por edificações irregulares que ignoraram a existência dos ramais condominiais bem como a total ausência de gestão pelo poder público local, o que teria trazido a Pelotas um modelo de saneamento precursor na abordagem da sustentabilidade. Espera-se que a elaboração de critérios, objetivo deste artigo, possa contribuir na etapa de entrevistas e que assim possa ser realizado um trabalho que proponha a reestruturação do atual sistema condominial da COHAB Lindóia, voltando a se conquistar o status de um sistema comprometido com a sustentabilidade ambiental.

\section{REFERÊNCIAS}

ACSELRAD, Henri. Discursos da Sustentabilidade Urbana. R. B. Estudos Urbanos e Regionais $n^{\circ}$ 1, P.1, 1999

CHIARELLI, Lígia Maria Ávila. Habitação social em Pelotas (1987 - 2010) Influências das políticas públicas na promoção de Conjuntos Habitacionais. 2014. Tese (Doutorado)Pontifícia Universidade Católica do Rio Grande do Sul, PUCRS, Faculdade de filosofia e ciências humanas, Programa de Pós-Graduação em História.

MEDVEDOVSKI, Nirce. A vida sem condomínio: configuração e serviços públicos urbanos em conjuntos habitacionais de interesse social. 1998.493f. Tese (Doutorado) Faculdade de Arquitetura e Urbanismo, Universidade de São Paulo, São Paulo, 1998.

MELO, José Carlos. Sistema Condominial de esgotos -Razões, teoria e prática. Recife, Caixa Econômica Federal, 1994.

MINISTÉRIO DO MEIO AMBIENTE. Agenda 21 Brasileira. Brasília, 2003. Disponível em: <http://www.mma.gov.br/responsabilidade-socioambiental/agenda-21/agenda-21brasileira.html>.Acesso em: 21 abril. 2019.

VASCONCELOS, Ronald Fernando. Descentralização-Político Administrativa na Cidade do Recife - O Caso do Esgotamento Sanitário na Gestão da Frente Popular 1986- 1988. Dissertação (Mestrado de Desenvolvimento Urbano e Regional) Universidade Federal de Pernambuco - Centro de Artes e Comunicação - Departamento de Arquitetura e Urbanismo. Recife, 1995.

SCARAMUSSA, Solange; HENKES, Jairo. A utilização do sistema condominial de esgotamento sanitário como política pública para universalização do atendimento com redes de esgoto: O exemplo clássico do Distrito Federal. Revista Gestão e Sustentabilidade Ambiental. Florianópolis, v.3, n.1, p. 310 - 339. abr.2014/set.2014

SACHS, Ignacy. Estratégias de Transição para do século XXI - Desenvolvimento e Meio Ambiente. São Paulo: Studio Nobel - Fundação para o desenvolvimento administrativo, 1993. 